\title{
Smart Cities: extrafiscalidade como indutora do desenvolvimento de cidades inteligentes
}

\author{
Smart Cities: extra-taxation as an inducer of the development of smart cities \\ Smart Cities: extra-tributación como inductor del desarrollo de las ciudades \\ inteligentes
}

\author{
Franco Guerino de Carli ${ }^{1}$ \\ Lídia Maria Ribas ${ }^{1}$
}

Recebido em 30/10/2019; revisado e aprovado em 26/05/2020; aceito em 17/07/2020

DOI: http://dx.doi.org/10.20435/inter.v22i1.2794

\begin{abstract}
Resumo: O presente artigo aborda as cidades inteligentes, levando em consideração a criação e o desenvolvimento dos direitos humanos e o desenvolvimento sustentável como um direito humano. As cidades inteligentes representam uma forma de promoção de vida digna aos seus moradores, pois elas adquirem essa denominação em razão do atendimento de protocolos que visam à obtenção de mobilidade, de utilização de tecnologia e energia limpa, de realização de ações que promovem o desenvolvimento social e econômico de forma justa, de urbanismo, de governança, entre outros. O objetivo geral da pesquisa é verificar a existência de relação entre a concepção de cidades inteligentes e a promoção dos direitos humanos, bem como a utilização da extrafiscalidade como indutora do desenvolvimento de cidades inteligentes. A fim de responder a esse questionamento, um dos possíveis instrumentos a serem utilizados é a tecnologia, para transformar os centros urbanos em ambientes mais humanos. Para isso, a pesquisa aborda a importância da implementação do uso de Tecnologias da Informação e Comunicação (TICs), presente nas cidades denominadas "inteligentes", como forma de se oportunizar mais igualdade aos moradores das cidades, maior dignidade e qualidade de vida, garantindo, assim, uma maior efetividade aos direitos humanos das pessoas que vivem em centros urbanos. Para a consecução desses objetivos, foi utilizado o método hipotético-dedutivo de abordagem, com a realização de pesquisa bibliográfica e documental. Chegou-se à conclusão de que a cidade que consegue implementar aspectos do conceito de Cidades Inteligentes e Humanas oportuniza mais igualdade aos moradores, maior dignidade e qualidade de vida, garantindo, assim, uma maior efetividade aos direitos humanos das pessoas que vivem em centros urbanos, com a criação de mecanismos de estímulos à adoção de posturas, por particulares, com a utilização da tributação - na modalidade extrafiscal.
\end{abstract}

Palavras-chave: cidades inteligentes; cidades sustentáveis; cidades humanas; direitos humanos; extrafiscalidade.

\begin{abstract}
This article addresses smart cities, taking into account the creation and development of human rights and sustainable development as a human right. Smart cities represent a way of promoting dignified life to their residents, as they acquire this name due to the compliance with protocols that aim at obtaining mobility, the use of technology and clean energy, the execution of actions that fairly promote social and economic development, urbanism, governance, among others. The general objective of the research is to verify the existence of a relationship between the design of smart cities and the promotion of human rights, as well as the use of extra-taxation as an inducer for the development of smart cities. To answer this question, one of the possible instruments to be used is technology, to transform urban centers into more human environments. For this, the research addresses the importance of implementing the use of Information and Communication Technologies (ICTS), present in cities called "smart", as a way of providing more equality to city dwellers, greater dignity, and quality of life, ensuring thus making human rights of people living in urban centers more effective. To achieve these objectives, we used the hypothetical-deductive method of approach, with bibliographic and documentary research. The conclusion is that the city that manages to implement aspects of the concept of Intelligent and Human Cities provides more equality to residents, greater dignity, and quality of life, thus ensuring greater effectiveness to the human rights of people living in urban centers, with the creation of mechanisms to encourage the adoption of attitudes, by individuals, with the use of taxation - in the extra-fiscal modality.
\end{abstract}

Keywords: smart cities; sustainable cities; human cities; human rights; extrafiscalidade.

\footnotetext{
${ }^{1}$ Universidade Federal de Mato Grosso do Sul (UFMS), Campo Grande, Mato Grosso do Sul, Brasil.
} 


\begin{abstract}
Resumen: Este artículo aborda las ciudades inteligentes, teniendo en cuenta la creación y el desarrollo de los derechos humanos y el desarrollo sostenible como un derecho humano. Las ciudades inteligentes representan una forma de promover una vida digna para sus residentes, ya que adquieren este nombre debido al cumplimiento de los protocolos que apuntan a obtener movilidad, usar tecnología y energía limpia, llevar a cabo acciones que promuevan el desarrollo social y económico justo, urbanismo, gobernanza, entre otros. El objetivo general de la investigación es verificar la existencia de una relación entre el diseño de ciudades inteligentes y la promoción de los derechos humanos, así como el uso de impuestos extras como inductor para el desarrollo de ciudades inteligentes. Para responder a esta pregunta, uno de los posibles instrumentos a utilizar es la tecnología, para transformar los centros urbanos en entornos más humanos. Para ello, la investigación aborda la importancia de implementar el uso de las Tecnologías de la Información y la Comunicación (TICS), presentes en ciudades llamadas "inteligentes", como una forma de proporcionar más igualdad a los habitantes de las ciudades, mayor dignidad y calidad de vida, garantizando, por lo tanto, una mayor efectividad para los derechos humanos de las personas que viven en centros urbanos. Para lograr estos objetivos, se utilizó el método de enfoque hipotético-deductivo, con investigación bibliográfica y documental. Se concluyó que la ciudad que logra implementar aspectos del concepto de Ciudades Inteligentes y Humanas brinda más igualdad a los residentes, mayor dignidad y calidad de vida, garantizando, así, una mayor efectividad a los derechos humanos de las personas que viven en centros urbanos, con la creación de mecanismos para estimular la adopción de actitudes, por parte de los individuos, con el uso de impuestos, en la modalidad extra fiscal..
\end{abstract}

Palabras claves: ciudades inteligentes; ciudades sostenibles; ciudades humanas; derechos humanos; extrafiscalidad.

\title{
1 INTRODUÇÃO
}

O presente artigo pretende desenvolver o tema das cidades inteligentes, levando em consideração a extrafiscalidade como mecanismo indutor do desenvolvimento das cidades, o desenvolvimento sustentável e os direitos humanos.

As cidades inteligentes representam uma forma de promoção de vida digna aos seus moradores, pois elas adquirem essa denominação em razão do atendimento de protocolos que visam à obtenção de mobilidade, de utilização de tecnologia e energia limpa, de realização de ações que promovem o desenvolvimento social e econômico de forma justa, de urbanismo, de governança, entre outros.

O Brasil e o mundo, de forma geral, estão cada dia mais urbanizados. As cidades e os centros urbanos são hoje a "escolha" da maioria das pessoas para viver. Mas nem todos os habitantes das cidades vivem de forma digna, a maioria dos citadinos convive com dificuldades impostas pela forma como a cidade é ordenada. Diante desse fato, pensar as cidades e como elas estão (des) organizadas é fundamental quando se pensa na dignidade e na qualidade de vida das pessoas.

A pesquisa envolve os aspectos conceituais sobre Cidades Inteligentes e busca responder ao seguinte problema: "Qual a relação entre a concepção de cidades inteligentes e o respeito aos direitos humanos? A extrafiscalidade pode ser utilizada como indutora do desenvolvimento de cidades inteligentes?". A fim de responder a esse questionamento, um dos possíveis instrumentos a serem utilizados é o emprego da tecnologia e a criação de mecanismos de estímulos à adoção de posturas, por particulares, com a utilização da tributação - na modalidade extrafiscal. A implementação de Tecnologias da Informação e Comunicação (TICS) é uma forma de possibilitar a diminuição de desigualdades sociais entre os moradores das cidades.

Com a disseminação da Internet, as pessoas passaram a ter acesso às mesmas informações e conhecimentos, sem distinção alguma entre as classes sociais a que pertencem. O uso das TICs possibilita uma transformação positiva na melhoria de problemas das cidades; por exemplo, melhorando a mobilidade, diminuindo a poluição (meio ambiente saudável) e auxiliando na gestão pública de qualidade (eficiente). 
O Estado, por meio da extrafiscalidade, deveria passar a utilizar o tributo como um instrumento de regulação, propiciando mecanismos de estímulos à adoção de desenvolvimento e implementação do uso de tecnologias nas cidades, com o objetivo de alcançar determinados fins que são caros à humanidade, como a possibilidade de termos uma transformação das cidades em ambientes com qualidade de vida e que acompanhem os anseios da sociedade moderna.

O objetivo geral do estudo é verificar a existência de relação entre a concepção de cidades inteligentes e a promoção dos direitos humanos, bem como a utilização da extrafiscalidade como indutora do desenvolvimento de cidades inteligentes. Os objetivos específicos são: a) Analisar a formação histórica dos direitos humanos e a sua percepção no mundo contemporâneo; b) Apresentar o direito a um meio ambiente sustentável como direito humano fundamental; c) Descrever as principais características das cidades inteligentes e a relação com o respeito aos direitos humanos de seus moradores; e d) Verificar se mecanismos de estímulos à adoção de posturas, por particulares, por meio da tributação - na modalidade extrafiscal -, pode ser fator de indução de desenvolvimento de cidades mais inteligentes e humanas.

Para apresentar o tema, o artigo está dividido em três seções. Na primeira, busca-se apresentar temas acerca do desenvolvimento e dos direitos humanos e sua relação advinda da Conferência das Nações Unidas sobre o Meio Ambiente Humano, realizada em Estocolmo, em 1972. O desenvolvimento sustentável apresenta-se como uma boa resposta à indagação sobre como equacionar o meio ambiente e o desenvolvimento econômico, pois une os conceitos desenvolvimento e respeito ao meio ambiente, garantindo-se, assim, o respeito ao direito humano daqueles que vivem principalmente em centros urbanos.

Na segunda seção, busca-se conceituar cidades inteligentes, além de demonstrar como a utilização de Tecnologias da Informação e Comunicação pode ser útil na melhoria da qualidade de vidas das pessoas, na medida em que possibilitam uma maior igualdade entre elas.

Na terceira seção, apresenta-se a temática acerca da extrafiscalidade e a possibilidade da utilização deste instrumento como indutor do desenvolvimento de cidades inteligentes. Para a realização do artigo, foi utilizado o método dedutivo de abordagem, com a realização de pesquisa bibliográfica e documental.

A investigação proposta será desenvolvida sob o enfoque predominantemente qualitativo. A pesquisa seguirá a caracterização proposta por Vergara (1998), sendo a pesquisa classificada como bibliográfica, com base em material publicado em livros, artigos publicados de forma impressa ou por meio eletrônico. Também serão utilizadas legislações sobre o tema objeto do estudo. O método a ser utilizado é o hipotético-dedutivo, que permite analisar nosso objeto para tirarmos conclusões (MEZZAROBA, 2017).

\section{DIREITOS HUMANOS E DESENVOLVIMENTO}

O conceito de direitos humanos abrange uma vasta gama de categorias de direitos que se unem na persecução da dignidade humana. Entre eles, podem ser citados o direito à vida, à liberdade, à educação, à moradia, à participação na política, à igualdade, entre outros. O direito a um meio ambiente saudável é, sem dúvida, direito humano fundamental que influencia sobremaneira a dignidade humana.

Tanto os direitos humanos quanto as cidades são decorrentes da construção histórica da civilização. É no âmbito da cidade que vários direitos humanos são protegidos e/ou 
negligenciados, na medida em que a cidade é um espaço de relações sociais, comerciais, financeiras e institucionais.

De acordo com Piovesan (2014, p. 204), a Declaração de 1948 introduziu a chamada "concepção contemporânea de direitos humanos, marcada pela universalidade e pela indivisibilidade desses direitos", sendo que a universalidade tem relação com a sua titularidade ter como requisito apenas a condição humana. A autora sustenta ainda que "os direitos humanos compõem uma unidade indivisível, interdependente e inter-relacionada" (PIOVESAN, 2014, p. 204). Tanto isso é verdade que a Declaração de Direitos Humanos de Viena, de 1993, reitera a concepção da Declaração de 1948, quando, em seu $\S 5^{\circ}$, dispõe: "Todos os direitos humanos são universais, interdependentes e inter-relacionados. A comunidade internacional deve tratar os direitos humanos globalmente de forma justa e equitativa, em pé de igualdade e com a mesma ênfase". A mesma declaração de Viena afirma a interdependência entre os valores dos direitos humanos, da democracia e do desenvolvimento. De acordo com Silveira e Rocasolano (2010, p. 239), "o documento final de Viena incorporou como um de seus princípios o caráter universal dos direitos humanos, convertendo também o direito ao desenvolvimento em direito universal e parte integrante dos direitos humanos".

Se tanto o direito a um meio ambiente equilibrado e saudável quanto o direito ao desenvolvimento são considerados direitos humanos e, portanto, devem ser tratados de forma equitativa, como realizar essa inter-relação? O desenvolvimento sustentável parece ser uma boa resposta a esse questionamento, pois une os conceitos desenvolvimento e respeito ao meio ambiente.

A Conferência das Nações Unidas sobre Meio Ambiente e Desenvolvimento (CNUMAD), também conhecida como Eco 92 ou Rio 92, elegeu o desenvolvimento sustentável como meta a ser buscada e respeitada por todos. O princípio 4 da Declaração do Rio estabelece: "Para alcançar o desenvolvimento sustentável, a proteção ambiental constituirá parte integrante do processo de desenvolvimento e não pode ser considerada isoladamente deste". Dessa forma, desenvolvimento e proteção ambiental devem caminhar juntos, com harmonia e respeito mútuo, não sendo possível atualmente a escolha entre um e outro.

A relação entre direitos humanos e meio ambiente tem como marco no Direito Internacional a Conferência das Nações Unidas sobre o Meio Ambiente Humano, realizada em Estocolmo, em 1972. A partir da proclamação inicial, o documento da Conferência já coloca o meio ambiente saudável como condição de qualidade de vida:

A Conferência das Nações Unidas sobre o Meio Ambiente Humano, reunida em Estocolmo de 5 a 16 de junho de 1972, e, atenta à necessidade de um critério e de princípios comuns que ofereçam aos povos do mundo inspiração e guia para preservar e melhorar o meio ambiente humano, proclama que:

1. O homem é ao mesmo tempo obra e construtor do meio ambiente que o cerca, o qual Ihe dá sustento material e lhe oferece oportunidade para desenvolver-se intelectual, moral, social e espiritualmente. Em larga e tortuosa evolução da raça humana neste planeta chegouse a uma etapa em que, graças à rápida aceleração da ciência e da tecnologia, o homem adquiriu o poder de transformar, de inúmeras maneiras e em uma escala sem precedentes, tudo que o cerca. Os dois aspectos do meio ambiente humano, o natural e o artificial, são essenciais para o bem-estar do homem e para o gozo dos direitos humanos fundamentais, inclusive o direito à vida mesma. (ONU, 1972, s.p.).

Na parte seguinte do documento, são elencados princípios, entre os quais, o primeiro contempla o direito a um meio ambiente de qualidade, como essencial a uma vida digna: 
Princípio 1- O homem tem o direito fundamental à liberdade, à igualdade e ao desfrute de condições de vida adequadas em um meio ambiente de qualidade tal que lhe permita levar uma vida digna e gozar de bem-estar, tendo a solene obrigação de proteger e melhorar o meio ambiente para as gerações presentes e futuras. (ONU, 1972, s.p.).

Após esse marco inicial, várias foram as disposições que consideram o direito a um meio ambiente saudável; hoje resta consolidado o entendimento de ser o direito a um meio ambiente saudável um direito humano fundamental.

No Brasil, de forma gradual e contínua, as legislações foram sendo elaboradas, estabelecendo-se, assim, a Política Nacional do Meio Ambiente, com órgãos de controle em nível nacional, regionais e locais, responsáveis pela execução de programas e projetos relativos à proteção da qualidade ambiental e pela gestão ambiental.

A proteção ao meio ambiente foi elevada à categoria constitucional a partir de 1988, tendo sido dedicado um capítulo da Carta Magna exclusivamente para tratar deste tema. O constituinte originário teve a preocupação de tutelar os bens ambientais, tendo em vista a necessidade de construção de uma sociedade sustentável.

Quanto ao direito ao desenvolvimento, a Declaração sobre o Direito ao Desenvolvimento, aprovada pela Assembleia Geral da Organização das Nações Unidas em 1986, consolidou o entendimento de que o desenvolvimento é direito fundamental de cada um e da humanidade como um todo:

Artigo 1 - O direito ao desenvolvimento é um direito humano inalienável em virtude do qual toda pessoa humana e todos os povos estão habilitados a participar do desenvolvimento econômico, social, cultural e político, a ele contribuir e dele desfrutar, no qual todos os direitos humanos e liberdades fundamentais possam ser plenamente realizados. (ONU, 1986, s.p.).

Como se pode observar da própria redação dos documentos citados, a qualidade de vida corresponde ao objetivo do direito ao desenvolvimento e também do direito ambiental. Portanto, deve ser afastada a equívoca ideia de que as normas de proteção ambiental se configuram em um obstáculo ao desenvolvimento econômico e tecnológico. Na realidade, ambos devem caminhar juntos com o objetivo comum de melhora da qualidade de vida das pessoas em geral.

Considerando esse entendimento, a Constituição Federal, em seu art. 170, determinou que a proteção ao meio ambiente se enquadra como um dos princípios norteadores da Ordem Econômica Brasileira. Não há, portanto, como negar o visível caráter econômico do Direito Ambiental. A partir dessa percepção, faz-se necessário um perfeito equacionamento dos princípios do Direito Ambiental com os princípios econômicos, a fim de compreender a necessidade da manutenção de um meio ambiente ecologicamente equilibrado para a garantia de uma mínima qualidade de vida aos homens para as presentes e futuras gerações.

Além disso, a Constituição Federal, em seu artigo 225, preleciona: "Todos têm direito ao meio ambiente ecologicamente equilibrado, bem de uso comum do povo e essencial à sadia qualidade de vida, impondo-se ao Poder Público e à coletividade o dever de defendê-lo e preserválo para as presentes e futuras gerações" (BRASIL, 1988, s.p.). O legislador constituinte erigiu o meio ambiente à categoria de bem de uso comum do povo, asseverando, assim, ser direito de todos tê-lo de maneira ecologicamente equilibrada, e, em contrapartida, determinou que sua defesa e preservação para as presentes e futuras gerações são deveres do Poder Público e de toda a coletividade. Nesse sentido, a interpretação do direito ambiental deve ser feita sempre levando em consideração os aspectos econômicos e sociais. Ele deve ser compreendido como 
instrumento capaz de assegurar uma melhor qualidade de vida à população, conciliando o desenvolvimento econômico e social com a proteção ao meio ambiente.

A partir dessa dupla preocupação - com o meio ambiente e também com o desenvolvimento - é que surgiu o conceito de desenvolvimento sustentável. Trata-se de um termo relativamente novo, tendo sido utilizado pela primeira vez em 1987, no relatório "Nosso Futuro Comum", pela Comissão Mundial sobre o Meio Ambiente e o Desenvolvimento, da ONU. O documento, também denominado Relatório Brundtland, em razão de a comissão ter sido presidida por Gro Brundtland (ex-primeira-ministra da Noruega), conceituou desenvolvimento sustentável como aquele "que encontra as necessidades atuais sem comprometer a habilidade das futuras gerações de atender suas próprias necessidades" (ONU, 1987, s.p.).

Um mundo assolado pela pobreza, pela desigualdade e pela destruição ambiental é o que justifica a adoção do desenvolvimento de forma sustentável, ou seja, um desenvolvimento que não esteja preocupado apenas com questões econômicas e financeiras, mas que tenha como objetivo a busca de justiça social, com repartição das riquezas e cuidado com o ambiente.

No mundo atual, em que alguns consomem muito e outros - a maioria - sofrem com a falta daquilo que é mais básico para a sobrevivência, o desenvolvimento sustentável aparece como instrumento de atendimento das necessidades humanas, seja pelo incremento do potencial produtivo, seja pela garantia de oportunidades iguais para todos.

Layrargues entende que a sustentabilidade, por meio de políticas ambientais, é importante para regular o acesso aos recursos ambientais, para que haja a repartição tanto das riquezas quanto dos prejuízos oriundos do uso dos produtos e serviços ambientais:

Então o que está em jogo para a construção da sustentabilidade também é o estabelecimento de políticas ambientais que criem regras de convívio social reguladoras do acesso e do uso dos recursos ambientais, definindo os critérios para a repartição dos benefícios e prejuízos das riquezas geradas pelo uso dos produtos e serviços ambientais, bem como dos benefícios e prejuízos dos efeitos das políticas ambientais. Trata-se, afinal de contas, do estabelecimento de políticas situadas na interface entre a questão ambiental e justiça distributiva, tendo como horizonte e supressão das desigualdades. (LAYRARGUES, 2009, p. 21).

Segundo o Relatório Brundtland, o desenvolvimento sustentável não deve pôr em risco os sistemas naturais que sustentam a vida na Terra: a atmosfera, as águas, os solos e os seres vivos. Ele constitui um processo de mudança no qual a exploração dos recursos, o direcionamento dos investimentos, a orientação do desenvolvimento tecnológico e a mudança institucional estão em harmonia e reforçam o atual e futuro potencial para satisfazer as aspirações e necessidades humanas. Dessa forma, partindo do conceito elaborado pelo relatório, o desenvolvimento sustentável é aquele que visa atender às necessidades atuais permitindo às gerações futuras atenderem às suas. Ou seja, o desenvolvimento deve ser pensado de forma a não comprometer o meio ambiente, para que ele possa ser usufruído pelas próximas gerações.

A correlação entre desenvolvimento e proteção ambiental levou a uma crescente conscientização mundial. E, em 1992, foi elaborada a Agenda 21, como culminância dos movimentos iniciados em 1972, em Estocolmo. Na Agenda 21, foi fortalecida a relação entre o meio ambiente e o desenvolvimento, e a necessidade imperativa para o desenvolvimento sustentável foi vista e reconhecida em todo o mundo. Além disso, a Agenda forjou um programa detalhado para afastar o mundo do atual modelo insustentável de crescimento econômico, privilegiando atividades que protejam e renovem os recursos ambientais. Entre as ações previstas, 
estão a proteção da atmosfera, o combate ao desmatamento e à desertificação; prevenção da poluição da água e do ar; detenção da destruição das populações de peixes e a promoção de uma gestão segura dos resíduos tóxicos.

A Agenda 21 não se preocupou apenas com as questões ambientais, mas levou em consideração, de forma bastante efetiva, também, as questões atinentes ao desenvolvimento, como as relacionadas com a pobreza e a dívida externa dos países em desenvolvimento; com padrões insustentáveis de produção e consumo; com pressões demográficas e com a estrutura da economia internacional. Além disso, o programa de ações previsto na Agenda recomendou formas de fortalecer o papel desempenhado por grupos de mulheres, organizações sindicais, agricultores, crianças e jovens, povos indígenas, comunidade científica, autoridades locais, empresas, indústrias e ONGs, com o fim de atingir o desenvolvimento sustentável.

Alinhado ao projetado pela Agenda 21, Layrargues (2009, p. 23) afirma que a "sustentabilidade ambiental depende do enfrentamento simultâneo dos problemas ambientais derivados da pobreza e da riqueza". De acordo com o autor, o planeta não aguenta mais o padrão de produção e consumo atual, não sendo possível imaginar uma solução em que apenas a poluição da pobreza seja enfrentada. É preciso que os países desenvolvidos assumam a responsabilidade que lhes cabe na destruição ambiental.

Mudanças são fundamentais, sendo necessária a abolição de iniciativas de "desenvolvimento", ajustes e reformas econômicas que mantêm o atual modelo de crescimento com seus terríveis efeitos sobre o ambiente e a diversidade de espécies, incluindo a humana.

Conforme já defendia Aristóteles (2002), em sua obra "A política", o homem é um ser social, político. Assim, não há como pensar em dignidade humana sem pensar na vida do homem na pólis, na cidade, local onde ele vive e desenvolve suas atividades, onde ele se relaciona com os demais e exerce seus direitos e obrigações.

Portanto, pensar o desenvolvimento sustentável nas cidades é pensar no desenvolvimento humano, é pensar na qualidade de vida daqueles que residem nas cidades. Aliado a isso, pensar em cidade inteligente significa pensar a cidade a partir do seu fator humano, afinal, essa "inteligência" deve se dirigir ao bom convívio e ao bem-estar de seus habitantes.

\section{CIDADES INTELIGENTES}

A realidade atual das cidades, principalmente dos grandes centros urbanos, vai de encontro ao que se colocou nos tópicos anteriores: hoje as cidades não dispõem de transporte público de qualidade; a mobilidade urbana é prejudicada; os centros de convívio público estão degradados e sem cuidados; existem zonas que demarcam e delimitam setores sociais, com a construção de guetos, geralmente localizados longe do centro; os níveis de poluição são altos, entre outros. Ainda há um longo caminho a ser percorrido para que tenhamos cidades inteligentes e humanas. Para Morenilla (2016), sustentabilidade, mobilidade e igualdade social são os três desafios das grandes cidades latino-americanas.

Em termos gerais, o conceito de cidades inteligentes e sustentáveis faz referência ao uso extensivo de novas tecnologias, as Tecnologias da Informação e Comunicação (TICs), destinadas a melhorar a qualidade de vida da população, o que passaria necessariamente por uma maior conservação e cuidado com o meio ambiente e a redução da desigualdade social.

Muitas são as contribuições teóricas provindas das cidades inteligentes e cidades sustentáveis. Cidade sustentável é o assentamento humano constituído por uma sociedade 
com consciência de seu papel de agente transformador dos espaços e cuja relação não se dá pela razão natureza-objeto, e sim por uma ação sinérgica entre prudência ecológica, eficiência energética e equidade socioespacial (ROMERO, 2007, apud ABDALA et al., 2014).

Uma cidade inteligente se forma quando investimentos em capital humano e social, assim como em tradicionais (transporte) e modernas (TICS) infraestruturas, alimentam um crescimento econômico sustentável e a qualidade de vida, com uma gestão sábia dos recursos naturais, por meio de uma governança participativa (CARAGLIU; DEL BO; NIJKAMP, 2011, apud ABDALA et al., 2014).

Com a popularização da Internet, possibilitou-se a implementação e utilização das TICs, não mais utilizadas somente pelas indústrias nos processos de automação pelos governos, no gerenciamento e na publicidade dos comércios, ao oferecer alguns serviços, mas também por toda a população, melhorando a transmissão e o acesso ao conhecimento, reduzindo a desigualdade social entre as diversas classes sociais.

A adoção de tecnologias das cidades inteligentes não significa a solução de todos os problemas das pessoas que vivem nas cidades, mas certamente elas podem significar a solução ou a mitigação de vários problemas, como a precariedade do transporte público ou da saúde pública, por exemplo, trazendo resultados na melhora da qualidade de vida de todos.

O desenvolvimento de uma cidade inteligente, ou smart city, parte da perspectiva de que a tecnologia é fator indispensável para que as cidades possam se modernizar e oferecer melhor infraestrutura à população. Além disso, esse conceito tem se mostrado fundamental no processo de tornar os centros urbanos mais eficientes e de oferecer boa qualidade de vida e gestão de recursos naturais por meio de um processo participativo (ANDRADE; GALVÃO, 2016, p. 5).

Aieta (2016), ao abordar o tema "cidades inteligentes", assevera que hoje prevalece nas zonas urbanas a arquitetura do medo, que provoca assombros, como nas propostas hobbesianas; essa arquitetura se reflete nas incontáveis grades das residências, na vida em condomínios. Para a autora, a cidade deve ser basicamente o lugar de habitação, e a organização da cidade deve atender a uma função social e fundamental que prevalece sobre as demais: "[...] dar habitação, assegurar os direitos sociais como um todo, atendendo as necessidades humanas de sobrevivência, de existência e também de felicidade" (AIETA, 2016, p. 162).

A grande concentração de população nas cidades traz consigo um ônus, a infraestrutura das cidades não acompanha o seu crescimento. As pessoas vivem em sua maioria distantes dos serviços de saúde, educação e mobilidade urbana.

$\mathrm{O}$ adensamento populacional traz consigo um ônus, pois nem sempre a infraestrutura urbana acompanha o crescimento da cidade. Muitas pessoas vivem em assentamentos subnormais, com pouco acesso aos serviços de saúde, educação e mobilidade urbana. Esta última, inclusive, pode ser um fator determinante no crescimento desordenado, pois com os altos valores das moradias próximas aos centros urbanos, a população de instala cada vez mais longe dos mesmos, exigindo assim que a infraestrutura chegue nestes locais. Sendo assim, o desafio de se planejar, repensar e atender estas áreas se faz presente nas grandes cidades, que precisam ser mais inteligentes e humanas. (ANDRADE; GALVÃO, 2016, p. 2).

Para a caracterização de uma cidade como inteligente, necessário se faz observar alguns eixos, como a economia, meio ambiente, transporte/mobilidade, gestão pública e qualidade de vida.

O conceito não está fechado e, atualmente, pode significar formas de gestão urbana alicerçadas em TIC. Nesse sentido, 
As cidades são consideradas inteligentes quando são identificadas contendo investimentos inteligentes ao longo dos eixos: economia, mobilidade, meio ambiente, recursos humanos e estilos de vida inteligentes. Os significativos avanços tecnológicos e das tecnologias da informação e comunicação (TIC) agora fazem das plataformas tecnológicas embarcadas um instrumento potencialmente significativo para sensorizar e monitorar a funcionalidade e o desempenho das cidades, permitindo ampliar sobremaneira suas capacidades de gerenciar recursos com mais eficiência e prover conectividade e informações de forma transparente aos seus cidadãos e visitantes. Estas estratégias permitem também que se compreendam melhor os custos financeiros e ambientais de seus próprios consumos. Torna-se assim possível que os gestores urbanos criem novos serviços e melhorem aqueles já existentes coletando e analisando informações sobre infraestruturas essenciais, como energia, água, transporte e saúde, entre outros de interesse da comunidade local. (C40 SÃO PAULO CLIMATE SUMMIT, 2011, p. 32).

Um dos pilares de uma cidade inteligente é a mobilidade urbana. Segundo Fernandes (2016), uma mobilidade inteligente inclui várias dimensões: um sistema de transportes públicos que seja sustentável (eficiente ao nível energético e a preços acessíveis) e de fácil acesso a todos os pontos da cidade; um ambiente que seja propício à mobilidade não motorizada, tal como a bicicleta; boa acessibilidade às redes regionais e internacionais; e, ainda, disponibilidade de infraestruturas de TIC.

A mobilidade urbana pode ser um fator determinante no crescimento desordenado, pois, com os altos valores das moradias próximas aos centros urbanos, a população se instala cada vez mais longe deles, exigindo, assim, que a infraestrutura chegue nestes locais ou que se disponibilize um serviço de transporte ao alcance de todos. Sendo assim, o desafio de se planejar, repensar e atender estas áreas se faz presente nas grandes cidades, que precisam ser mais inteligentes e humanas (ANDRADE; GALVÃO, 2016).

As cidades deverão passar por um processo de mudança de transporte individual para o uso de um transporte coletivo, como forma de solucionarmos um grande problema dos centros urbanos. Uma nova forma de governança é necessária para as cidades:

As novas formas de governança metropolitana que vêm surgindo como tendência mundial, precisam provar a sua efetividade em termos de equacionar os verdadeiros problemas metropolitanos. Ou seja, além de se caracterizarem pela legitimidade política (pois são embasadas no próprio protagonismo dos atores públicos e privados), as novas formas de governança regional e metropolitana deveriam reduzir os congestionamentos, a poluição ambiental e proporcionar um conjunto de projetos voltados para a competitividade sistêmica das cadeias produtivas regionais, para mencionar alguns dos desafios. (KLINK, 2009, p. 223).

Conforme Weiss (2013), a UN-Habitat (2012) determinou algumas perspectivas sobre as cidades, para que elas sejam consideradas inteligentes e humanas:

a) o desenvolvimento das infraestruturas, que forneça instalações públicas adequadas - ruas e estradas, saneamento básico, energia e tecnologias da informação e comunicação - a fim de melhorar as condições de vida urbana e incrementar a produtividade, mobilidade e conectividade;

b) produtividade, que contribua para o crescimento e desenvolvimento econômico, gerando resultados financeiros positivos, fornecendo postos de trabalho decentes e oportunidades iguais para todos;

c) qualidade de vida, pelo uso adequado dos espaços públicos, a fim de incrementar a coesão da comunidade, sua identidade cívica e que propicie segurança à vida e à prosperidade; 
d) equidade e inclusão social, que garanta a distribuição e redistribuição equitativa dos benefícios gerados na cidade, reduza a pobreza e a incidência de favelas, proteja os direitos de minorias e grupos menos favorecidos, fortaleça a igualdade de gêneros e garanta a participação das pessoas nas esferas sociais, políticas e culturais, e;

e) sustentabilidade ambiental, que valorize a proteção dos ambientes urbanos e dos bens naturais, buscando o uso eficiente de energia e água minimizando as pressões sobre o planeta e os recursos naturais, por meio da geração de soluções criativas que visem manter e melhorar a qualidade do ambiente. (UN-HABITAT, 2012 apud WEISS, 2013, s. p.).

Buscar soluções inteligentes para o crescimento dos centros urbanos e os impactos negativos trazidos por este é medida que se impõe. Nesse sentido,

A busca por soluções inteligentes para o enfrentamento dos desafios do crescimento urbano acelerado e seus impactos traz o conceito de smart city, que é envolvido em uma nova abordagem para mitigar e tratar os problemas nas cidades, visando que a mesma seja mais sustentável e que conte com a efetiva participação da população em sua construção e desenvolvimento. (ANDRADE; GALVÃO, 2016, p. 3).

O conceito de cidades inteligentes, que busca tratar os problemas das cidades objetivando que elas sejam mais sustentáveis, é o caminho mais acertado a ser tomado. Nesse sentido, o artigo 2o do Estatuto da Cidade, Lei 10.257/2001 informa:

Art. 2ำ A política urbana tem por objetivo ordenar o pleno desenvolvimento das funções sociais da cidade e da propriedade urbana, mediante as seguintes diretrizes gerais:

I - garantia do direito a cidades sustentáveis, entendido como o direito à terra urbana, à moradia, ao saneamento ambiental, à infra-estrutura urbana, ao transporte e aos serviços públicos, ao trabalho e ao lazer, para as presentes e futuras gerações;

$[\ldots]$

IV - planejamento do desenvolvimento das cidades, da distribuição espacial da população e das atividades econômicas do Município e do território sob sua área de influência, de modo a evitar e corrigir as distorções do crescimento urbano e seus efeitos negativos sobre o meio ambiente;

$\checkmark$ - oferta de equipamentos urbanos e comunitários, transporte e serviços públicos adequados aos interesses e necessidades da população e às características locais; (BRASIL, 2001, s.p.).

Fatores como a falta de mobilidade urbana podem trazer consequências para a queda da qualidade de vida das pessoas e também reflete na economia. Costa (2015) apresenta alguns exemplos do impacto na economia decorrente de uma mobilidade urbana deficiente: a área da saúde e da previdência social é diretamente afetada pela ocorrência de acidentes, que, muitas vezes, tornam o cidadão dependente do Estado. Também, segundo o autor, pode-se mencionar o grande aumento do tempo de deslocamento de casa para o trabalho, fator que gera prejuízo para empresas devido a uma potencial redução de desempenho dos funcionários, seja por atrasos, seja pelo cansaço.

Podem ser destacados outros problemas oriundos da mobilidade nas cidades, como os altos índices de poluição (atmosférica e sonora), os grandes congestionamentos (principalmente em horários de pico e próximo aos principais pontos de interesse) e a falta de integração entre os modais de transporte disponíveis. Além disso, destaca-se a priorização do transporte individual, expressa tanto nas ampliações viárias visando à melhoria de circulação quanto na construção de inúmeros estacionamentos. Todos esses fatores têm contribuído para a queda da qualidade de vida nos centros urbanos (ANDRADE; GALVÃO, 2016). 
Em países desenvolvidos, o transporte em massa vem sendo priorizado como fator para melhorar problemas com a mobilidade urbana e, em razão de sua qualidade, mostra-se efetivo como alternativa ao transporte individual. Diversamente, em países em desenvolvimento, o uso de veículos individuais está cada vez mais presente, podendo ser atribuído à causa do aumento do número de veículos, diante da má qualidade do transporte público.

A criação de smart cities é promissora nesse contexto, pois, paralelamente aos desafios mencionados, existe um avanço também sem precedentes da Tecnologia da Informação e do seu emprego em atividades comuns. A colisão entre o crescimento das cidades e o fluxo massivo de dados sobre elas e seus cidadãos permitirá a transformação do ambiente urbano em um laboratório cívico, um lugar no qual a tecnologia é adaptada de formas inovadoras para atender às necessidades locais. Este novo conceito tem o potencial de modificar completamente as relações entre a comunidade e os serviços urbanos (ANDRADE; GALVÃO, 2016).

Guimarães (2018, p. 121), formula um conceito de cidade inteligente que se adapta muito bem às questões levantadas na presente pesquisa. Para ele, Cidade Inteligente é uma cidade que tem o cidadão empoderado como protagonista e beneficiário de suas ações e as tecnologias de informação e comunicação como coadjuvantes principais e meios habilitadores para uma gestão pública transparente, participativa, responsiva e efetiva. É uma cidade que se renova e inova de maneira integrada, sistêmica e sistemática, na busca do bem comum da sociedade e de suas futuras gerações.

A tecnologia pode aumentar a eficiência na resolução dos problemas relacionados à mobilidade urbana, bem como em outras áreas. É importante pontuar que as cidades inteligentes têm um papel importante não só do ponto de vista social, por aproximar seus cidadãos da gestão, mas também econômico. Isto porque os investimentos em soluções podem partir de grandes empresas, universidades e organizações que, por meio de sua colaboração, podem atrair outras melhorias para as cidades (ANDRADE; GALVÃO, 2016).

Importante destacar que nem sempre a implementação do conceito de Cidade Inteligente e Humana requer infraestruturas sofisticadas e complexas, podendo ser feita por meio do uso de tecnologia simples, aproveitando-se das sugestões da população local, desde que ela tenha a oportunidade de participar da concepção e gestão destas tecnologias (COSTA; OLIVEIRA, 2016; DE FILLIPI, 2015; OLIVEIRA; CAMPOLARGO, 2015). Nesse sentido, a administração municipal que possibilita a criação de serviços humanos inteligentes sem ter de fazer investimentos significativos (COSTA; OLIVEIRA, 2016) se destaca, proporcionando diminuição de gastos públicos.

Dessa forma, necessário se faz um novo planejamento urbano, com a introdução de conceitos de cidade inteligente e observando-se as necessidades de cada cidade, sem deixar de lado os anseios e a participação da população neste processo; eis que o respeito e a implementação efetiva dos direitos humanos estão intimamente ligados à concepção de cidade inteligente. A participação das pessoas da cidade é fundamental no processo de mudança das cidades. A partir disso, surge a temática da extrafiscalidade, mecanismo a ser utilizado como indutor do desenvolvimento de cidades inteligentes.

\section{EXTRAFISCALIDADE PARA O DESENVOLVIMENTO DE CIDADES INTELIGENTES}

A extrafiscalidade é um instrumento que pode ser utilizado para a proteção dos objetivos almejados em diversas áreas defendidas pelo Estado; por exemplo, para o alcance da 
sustentabilidade. Seria então, um mecanismo de natureza tributária de intervenção do Estado na ordem econômica, com o objetivo de incentivar melhores condutas sóciais e ambientais e inibir comportamentos econômicos geradores de externalidades negativas.

Baleeiro (1999, p. 576-7) assim discorre sobre o assunto:

Costuma-se denominar de extrafiscal aquele tributo que não almeja, prioritariamente, prover o Estado dos meios financeiros adequados a seu custeio, mas antes visa a ordenar a propriedade de acordo com a sua função social ou intervir em dados conjunturais (injetando ou absorvendo a moeda em circulação) ou estruturais da economia. Para isso, o ordenamento jurídico, a doutrina e a jurisprudência têm reconhecido ao legislador tributário a faculdade de estimular ou desestimular comportamentos, de acordo com os interesses prevalecentes da coletividade, por meio de uma tributação progressiva ou regressiva, ou da concessão de benefícios fiscais.

A extrafiscalidade assume relevante tema de estudo na esfera tributária, sendo objeto de intensos debates na doutrina e jurisprudência sobre os seus resultados para o desenvolvimento econômico e social do país, como instrumento estatal de intervenção na economia e nas políticas sociais.

Martins e Teodorovicz (2011) apontam que a extrafiscalidade significa tudo que, dentro do âmbito de atuação dos tributos, alcance objetivos que escapem, primária ou secundariamente, à meta de arrecadação ou finalidade fiscal. Seguem dizendo que a extrafiscalidade pode ser entendida como a utilização de tributos (e por isso a ideia de fiscalidade), com o objetivo que não seja prioritariamente a arrecadação.

A primeira fase do reconhecimento da extrafiscalidade ocorreu como uma síntese entre o liberalismo econômico individualista (que pregava a função fiscal ligada à não intervenção e ao equilíbrio orçamentário) e o socialismo marxista (MARTINS; TEODOROVICZ, 2011). Nesse contexto, segundo os autores, surge Adolph Wagner, que vai apresentar um "meio-termo" entre as duas ideologias, não afastando a importância da "Função Fiscal". Este autor acrescentou também que os tributos poderiam ser utilizados para alcançar uma "finalidade social", qual seja a de redistribuição de receitas. A segunda fase do reconhecimento da extrafiscalidade atinge pleno reconhecimento pelos teóricos e políticos sobre a sua utilidade no combate às situações hostis vivenciadas a partir do século XX. Eis que a política de não intervenção estatal na economia não fazia mais sentido, e o papel diminuto da política social diante da política econômica começava a ser severamente questionado. Martins e Teodorovicz (2011) apontam que, nesse contexto econômico-social, surgiram novos estudiosos, como Lord John Maynard Keynes, que apresentou o contraponto do liberalismo econômico (ou economia clássica). A política fiscal passou a ser vista como mecanismo de superação das dificuldades na busca pelo desenvolvimento econômico e social.

O entendimento da função social dos tributos está atrelado ao uso do Sistema Tributário Nacional como um instrumento efetivo para que o Estado cumpra sua função social de promover o bem comum, a igualdade e a justiça, por meio do desenvolvimento social e econômico (FRIGO; MARTINS DA SILVA, 2008).

Vieira (2010) relaciona a tributação com os princípios, fundamentos e objetivos da Constituição Federal de 1988, afirmando que devem ser utilizados para assegurar o exercício dos direitos sociais e individuais, a liberdade, a segurança, o bem-estar, o desenvolvimento, a igualdade e a justiça como valores supremos de uma sociedade fraterna, pluralista e sem preconceitos. 
A Constituição Federal de 1988 consagra a extrafiscalidade tributária, ao regular, por exemplo, o tratamento diferenciado e favorecido para as microempresas e para empresas de pequeno porte (art. 146, III, d e parágrafo único), regime de tributação unificado denominado Simples Nacional, e o ITR progressivo para desestimular a manutenção de propriedade improdutiva (art. 153, §4으. I). Assim, a utilização da tributação para outros fins, que não o da mera e pura arrecadação, é um mecanismo que deveria ser mais utilizado como incentivo na promoção do desenvolvimento.

Os tributos de natureza extrafiscal podem ser uma importante ferramenta governamental para o fim da realização do bem comum, de forma a proporcionar programas sociais visando ao objetivo constitucional da redução das desigualdades sociais e, consequentemente, respeitando o fundamento da dignidade da pessoa humana. Como instrumento de intervenção estatal, a extrafiscalidade tributária pode se dar com a majoração da carga tributária, com vistas a desestimular comportamentos que sejam contrários aos interesses sociais, ou com a diminuição do encargo fiscal, para incentivar determinados comportamentos e ações benéficas ao desenvolvimento econômico e social.

A extrafiscalidade pode trazer benefícios importantíssimos ao desenvolvimento social, necessitando, no entanto, que ela se legitime na exata proporção da legitimidade dos objetivos visados, e isso se verificará, certamente, quando os fins visados passarem pela realização dos direitos fundamentais, reduzindo as desigualdades fáticas produzidas pelo modelo econômico vigente e alcançando a máxima densidade normativa do princípio da dignidade da pessoa humana (COSTA, 2016).

Hodiernamente, diante do atual cenário social, não se permite mais a segmentação de institutos como se inexistisse qualquer relação de conexão entre os elementos que a compõem. Nesse contexto, de complexidade, sobressai a necessidade do estudo do Direito Tributário sob o prisma da interdisciplinaridade, ou seja, o Direito Tributário deverá, cada vez mais, adaptarse a tendência à utilização da tributação extrafiscal para o desenvolvimento das cidades. Após Constituição de 1988, o sistema capitalista não se coaduna por si só, sendo indispensável a proteção ao meio ambiente com foco no desenvolvimento socioambiental e também para a consecução de objetivos para desenvolverem-se cidades inteligentes.

Para Leff (2006), a sustentabilidade ecológica aparece como um critério normativo para a reconstrução da ordem econômica, como uma condição para a sobrevivência humana e para um desenvolvimento durável; problematiza as formas de conhecimento, os valores sociais e as próprias bases da produção, abrindo uma nova visão do processo civilizatório da humanidade.

O Poder Público deve propiciar mecanismos de estímulos à adoção de posturas, por particulares, na busca pelo desenvolvimento e pela implementação de tecnologias para a melhoria das condições de vida das pessoas que vivem nas cidades, utilizando a tributação - na modalidade extrafiscal; por exemplo, concedendo isenções ou reduções de tributos municipais sobre propriedades ou atividades de especial interesse para consecução de cidades inteligentes. Também pode implementar mecanismos fiscais ou econômicos para incentivar ou desincentivar empresas, para que implementem ou não medidas que tenham relevância à inovação e ao emprego de novas tecnologias, como as que adotam medidas voltadas à melhora da qualidade de vida das pessoas.

O artigo 218, da Constituição Federal de 1988, dispõe que cabe ao Estado promover e incentivar o desenvolvimento científico, a pesquisa e a capacitação tecnológica no país. Com a publicação da Lei 10.973, em 2004, conhecida como a Lei de Inovação, o governo deu um 
passo bem grande ao dispor sobre incentivos à inovação e à pesquisa científica e tecnológica no ambiente produtivo, por isso essa Lei é considerada o marco regulatório da inovação no Brasil.

O governo, como mecanismo de incentivo à inovação, pode utilizar uma série de instrumentos de fomento, cujos principais são: os incentivos fiscais, a subvenção econômica, os financiamentos com juros mais baixos e a cooperação entre Instituições Científicas e Tecnológicas e empresas. O presente trabalho abordará os incentivos fiscais concedidos pelo governo às empresas que promovem a inovação tecnológica, conforme previsto no Capítulo III da Lei 11.196, de 21 de novembro de 2005. A Lei prevê benefícios fiscais para as empresas que desenvolvem inovação tecnológica.

Bepa (2011), citado por Piontkewicz, Freitas e Biz (2017), defende que a inovação deve ocorrer não somente por meio de novas tecnologias e processos, mas também de novas formas de organização e interações entre indivíduos. A inovação social tem foco na educação para desenvolver novas competências para futuras gerações e em serviços, como a saúde. Defende que, para manter um crescimento sustentável, inteligente e inclusivo, é necessário combater a pobreza, criar emprego, desenvolver capacidades e promover mudanças nos hábitos de produção e consumo.

A Lei 11.196/2005 prevê a concessão de incentivos com a finalidade de estimular o desenvolvimento tecnológico no Brasil. Entre os principais incentivos, destacam-se:

a) Além da dedutibilidade normal, exclusão adicional de 60\% a 100\% do lucro líquido e da base de cálculo da Contribuição Social sobre o Lucro Líquido (CSLL), dos gastos realizados com Pesquisa e Desenvolvimento;

b) Exclusão do lucro líquido e da base de cálculo da CSLL, de 50\% a 250\% dos gastos com projetos de pesquisa científica e tecnológica executada por ICT;

c) Redução de $50 \%$ do Imposto sobre Produtos Industrializados (IPI) incidente sobre equipamentos, máquinas, aparelhos, instrumentos e ferramentas adquiridos para pesquisa e desenvolvimento tecnológico. Tais máquinas não podem ser usadas na linha de produção;

d) Depreciação integral, no próprio ano da aquisição, de máquinas, equipamentos, aparelhos e instrumentos novos, destinados à pesquisa e ao desenvolvimento, para fins de apuração de IRPJ e CSLL;

e) Redução a zero da alíquota do Imposto de Renda Retido na Fonte nas remessas efetuadas para o exterior destinadas ao registro e à manutenção de marcas, patentes e cultivares.

f) Dedução da base de cálculo do IRPJ e da CSLL dos valores transferidos a microempresas e empresas de pequeno porte, destinados à execução de P\&D, de interesse e por conta da pessoa jurídica que promoveu a transferência.

Geralmente, os incentivos fiscais são bem recebidos pelas empresas, pois reduzem custos e tornam a empresa mais competitiva. No entanto, o que deveria ser algo benéfico e vantajoso financeiramente pode ter o efeito contrário se não forem observados todos os detalhes, condições e exigências necessários antes de a empresa tomar a decisão de utilizar os seus benefícios.

Alguns municípios brasileiros já legislaram acerca da temática proposta. Como exemplo, podemos citar a Lei n. 7.799, de 6 de junho de 2019, do Município de Petrópolis, RJ, que cria a Política Pública de incentivo à inovação e à pesquisa tecnológica, ao desenvolvimento sustentável e à consolidação dos ambientes de inovação nos setores produtivos e sociais da cidade de Petrópolis e dá outras providências. O artigo 1ㅇda Lei estabelece medidas de incentivo às atividades tecnológicas e de inovação realizadas pelas organizações e pelos cidadãos estabelecidos ou 
domiciliados no município de Petrópolis, visando promover o desenvolvimento econômico, social e ambiental e a melhoria dos serviços públicos municipais. O parágrafo 1ำ, do artigo 3ำ da Lei, estabelece a concessão de incentivos fiscais, os quais observarão o disposto na Lei 6.018/2013 do Município de Petrópolis, RJ.

Outra lei que merece destaque como medida de extrafiscalidade para incentivo ao desenvolvimento de cidade inteligente é a Lei Complementar n. 117, de 11 de junho de 2018, do Município de Juazeiro do Norte, CE, que dispõe sobre mecanismos, medidas e projetos para estímulo ao desenvolvimento científico, à pesquisa, à capacitação científica e tecnológica e à inovação no município, cria a Política Municipal de Ciência, Tecnologia e Inovação e estabelece diretrizes ao Plano Diretor de Tecnologias da Cidade Inteligente de Juazeiro do Norte.

O Art. 15, da Lei Complementar n. 117, de Juazeiro do Norte, prevê que o Poder Público Municipal moverá esforços para promover o desenvolvimento do potencial científico, tecnológico e inovador do Município, de forma a estabelecer incentivos de natureza fiscal às micro e pequenas empresas, assim classificadas de acordo com a Lei Complementar n. 123/06, que desenvolvam soluções a partir do uso intensivo de tecnologias avançadas ou mediante processos de inovação. A Lei, nos artigos 17 e 18, estabelece critérios com relação aos incentivos fiscais. Vejamos:

Art. 17 Fica instituído, no âmbito do Município de Juazeiro do Norte, incentivo fiscal relativo ao Imposto Sobre Serviços de Qualquer Natureza (ISSQN), a ser concedido de acordo com as disposições desta Lei Complementar, com o objetivo primordial de promover o empreendedorismo inovador de interesse da Municipalidade, com vistas ao atingimento dos objetivos da Política Municipal de CT\&I.

Art. 180 incentivo referido no artigo anterior somente será concedido a pessoas jurídicas que estejam rigorosamente em dia com suas obrigações fiscais perante a Municipalidade, que detenham plena habilitação jurídica e regularidade trabalhista, e que se caracterizem como Empresas de Base Tecnológica ou Empresas Inovadoras (nos termos do art. $3^{\circ}$, inc. VII desta Lei), consistindo em alíquota do Imposto Sobre Serviços de Qualquer Natureza (ISSQN) fixada em $2 \%$ (dois por cento), aplicável a todas as atividades constantes dos subitens do item 1 do art. 460 da Lei Complementar Municipal n 93, de 20 de Dezembro de 2013 (Código Tributário Municipal).

Parágrafo único - A pessoa jurídica beneficiária do incentivo referido neste artigo deverá, ao final de cada ano, apresentar à Prefeitura Municipal relatório completo com as atividades desenvolvidas e resultados alcançados, bem como, ao início de cada exercício, um Plano de Trabalho detalhado das atividades planejadas para o ano, a fim de que se delibere pela concessão ou continuidade do incentivo fiscal. (JUAZEIRO DO NORTE, 2018, s.p.).

Ainda é cedo para termos uma melhor compreensão se a legislação realmente possibilitará o incremento de melhorias no desenvolvimento das cidades. Porém, os Governos precisam seguir os exemplos de cidades que já legislaram acerca do tema, para garantir por meio da extrafiscalidade o surgimento de estudos, medidas que possibilitem a implementação dos conceitos de cidades inteligentes.

\section{CONSIDERAÇÕES FINAIS}

O presente trabalho teve por objetivo verificar como os direitos humanos podem ter uma maior aplicação em razão da utilização de práticas adotadas nas cidades inteligentes. Abordaramse também os direitos humanos, o direito ao desenvolvimento e a possibilidade da utilização da extrafiscalidade como indutora do desenvolvimento de cidades inteligentes. 
O estudo dos direitos humanos e do desenvolvimento, levando em consideração os aspectos conceituais e sua evolução para o atingimento do desenvolvimento sustentável como um direito humano, leva-nos à conclusão de que só se pode falar em desenvolvimento sustentável nas cidades se este se der nos níveis econômico, social e ambiental.

No que concerne às cidades inteligentes, verificou-se que é importantíssimo que os gestores públicos passem a implementar as TICs como forma de diminuir desigualdades sociais entre os moradores das cidades, pois o uso dessas tecnologias possibilitará a melhoraria de muitos problemas enfrentados pelas cidades, resultando em uma melhor qualidade de vida dos moradores.

O direito à cidade sustentável, como diretriz prevista no Estatuto da Cidade, exige um planejamento urbano diferenciado, com a introdução de conceitos de cidades inteligentes, uma vez que o respeito e a implementação efetiva dos direitos humanos estão umbilicalmente ligados à concepção de cidades inteligentes.

Acredita-se que um caminho a ser trilhado para o desenvolvimento de cidades inteligentes é o Poder Público criar mecanismos de estímulos à adoção de posturas, por particulares, na busca pelo desenvolvimento e implementação de tecnologias para a melhoria das condições de vida das pessoas que vivem nas cidades, utilizando a tributação - na modalidade extrafiscal -, medida que possibilitaria a implementação dos conceitos de cidades inteligentes, melhorando significativamente a qualidade de vida dos moradores das cidades.

Assim, cabe ao Estado criar ambientes para estimular o desenvolvimento de tecnologias que auxiliem o cidadão/empresa no processo de criação de novas soluções inteligentes para as cidades.

\section{REFERÊNCIAS}

ABDALA, L.; SCHREINER T.; COSTA, E.; SANTOS, N. Como as cidades inteligentes contribuem para cidades sustentáveis: uma revisão sistemática da literatura. International Journal of Knowledge Engineering and Management, Florianópolis, v. 3, n. 5, p. 98-120, mar./jun. 2014. Disponível em: http://via.ufsc.br/wpcontent/uploads/2016/06/Cidades-Inteligentes_Lucas.pdf. Acesso em: 3 jun. 2018.

AIETA, Vania Siciliano. Cidades Inteligentes: uma proposta de inclusão dos cidadãos rumo à ideia de "cidade humana". Direito da Cidade. Rio de Janeiro, v. 8, n. 4, p. 1622-43, 2016. Disponível em: http:// www.e-publicacoes.uerj.br/index.php/rdc/article/download/25427/19155. Acesso em: 4 jun. 2018.

ANDRADE, Josiane Nascimento; GALVÃO, Diogo Cavalcanti. O conceito de smart cities aliado à mobilidade urbana. Human E - Questões controversas do mundo contemporâneo, Recife, v. 10, n. 1, p. 1-19, 2016. Disponível em: http://humanae.esuda.com.br/index.php/humanae/article/view/478/150. Acesso em: 4 jun. 2018.

ARISTÓTELES. A política. Traduzido por Roberto Leal Ferreira. São Paulo: Martins Fontes, 2002.

BALEEIRO, Aliomar. Limitações constitucionais ao poder de tributar. 7. ed. Atualizada por Misabel Abreu Machado Derzi. Rio de Janeiro: Forense, 1999.

BRASIL. Constituição da República Federativa do Brasil. Promulgada em 5 de outubro de 1988. BrasíliaDF: Senado Federal, 1988.

BRASIL. Lei n. 10.257, de 10 de julho de 2001. Regulamenta os arts. 182 e 183 da Constituição Federal, estabelece diretrizes gerais da política urbana e dá outras providências. Brasília-DF, 2001. Disponível em: http://www.planalto.gov.br/ccivil_03/leis/LEIS_2001/L10257.htm. Acesso em: 3 jun. 2019. 
BRASIL. Lei n. 10.973, de 2 de dezembro de 2004. Dispõe sobre incentivos à inovação e à pesquisa científica e tecnológica no ambiente produtivo e dá outras providências. Brasília-DF, 2004. Disponível em: http:// www.planalto.gov.br/ccivil_03/_ato2004-2006/2004/lei/I10.973.htm Acesso em: 3 jun. 2019.

BRASIL. Lei n. 11.196, de 21 de novembro de 2005. Institui o Regime Especial de Tributação para a Plataforma de Exportação de Serviços de Tecnologia da Informação - REPES, o Regime Especial de Aquisição de Bens de Capital para Empresas Exportadoras - RECAP e o Programa de Inclusão Digital. Brasília-DF, 2005. Disponível em: http://www.planalto.gov.br/ccivil_03/_Ato2004-2006/2005/Lei/L11196. htm. Acesso em: 3 jun. 2019.

BRASIL. Ministério do Meio Ambiente. Agenda 21 global. Brasília-DF: MMA, 2018. Disponível em: http:// www.mma.gov.br/responsabilidade-socioambiental/agenda-21/agenda-21-global. Acesso em: 3 jun. 2018.

C40 SÃO PAULO CLIMATE SUMMIT. Síntese do C40 São Paulo Climate Summit 2011. São Paulo: Prefeitura de São Paulo, 2011. Disponível em: http://cetesb.sp.gov.br/proclima/wp-content/uploads/sites/36/2014/05/ smdu_usp_c40_pt_en.pdf. Acesso em: 3 jun. 2018.

COSTA, Carlos Adriano. A extrafiscalidade tributária na concretização do bem-estar social. In: PRÊMIO do Tesouro Nacional, 21., 2016, [s.l.], [s.n.]. Disponível em: https://sisweb.tesouro.gov.br/apex/cosis/ monografias/obtem_monografia/809. Acesso em: 7 jun. 2019.

COSTA, Carlos Augusto. Cidades inteligentes e big data. Cidades inteligentes e mobilidade urbana. Cadernos FGV Projetos, Rio de Janeiro, Ano 10, n. 24, p. 108-22, 2015. Disponível em: http://fgvprojetos.fgv.br/sites/ fgvprojetos.fgv.br/files/cadernos_fgvprojetos_smart_cities_bilingue-final-web.pdf. Acesso em: 4 jun. 2019.

COSTA, E. M.; OLIVEIRA, Á. D. Humane Smart Cities. In: FRODEMAN Robert; KLEIN, Julie Thompson; PACHECO, Roberto C. S. (Eds.). The Oxford Handbook of Interdisciplinarity. 2. ed. Oxford: Oxford University Press, 2016. p. 228-40.

DE FILIPPI, P. Community mesh networks: citizens' participation in the deployment of smart cities. In: HANDBOOK of Research on Social, Economic, and Environmental Sustainability in the Development of Smart Cities. IGI Global, 2015. p. 298-314.

FERNANDES, Maria Teresa Diogo da Silva Porto. Cidades Inteligentes: um novo paradigma urbano - estudo de um caso da cidade do Porto. 2016. 90 f. Dissertação (Mestrado em Gestão) - Universidade Católica Portuguesa, Porto, PT, 2016. Disponível em: https://repositorio.ucp.pt/bitstream/10400.14/21641/1/ Tese\%20cidades\%20inteligentes\%20-\%20estudo\%20de\%20caso\%20.pdf. Acesso em: 2 jul. 2018.

FRIGO, Claudemir; MARTINS DA SILVA, Ana Lucia. Função Social dos Tributos/Programa Nacional de Educação Fiscal. 3. ed. Brasília: ESAF, 2008.

GUIMARÃES, José Geraldo de Araujo. Cidades inteligentes: proposta de um modelo brasileiro multi-ranking de classificação. 2018. 278 f. Tese (Doutorado em Ciências) - Universidade de São Paulo, São Paulo, SP, 2018.

JUAZEIRO DO NORTE (Cidade). Lei Complementar Municipal n. 117, de 11 de junho de 2018. Dispõe sobre mecanismos, medidas e projetos para estímulo ao desenvolvimento científico, à pesquisa, à capacitação científica e tecnológica e à inovação no Município de Juazeiro do Norte, cria a Política Municipal de Ciência, Tecnologia e Inovação, estabelece diretrizes ao Plano Diretor de Tecnologias da Cidade Inteligente de Juazeiro do Norte e dá outras providências. Juazeiro do Norte, 2018. Disponível em: https://www.juazeiro. ce.gov.br/Imprensa/Diario-Oficial/Num4762-14062018/. Acesso em: 3 jun. 2019.

KLINK, Jeoren. Regionalismo e reestruturação urbana: uma perspectiva brasileira de governança metropolitana. Educação, Porto Alegre, v. 32, n. 2, p. 217-26, 2009. Disponível em: http://revistaseletronicas. pucrs.br/ojs/index.php/faced/article/download/5524/4019. Acesso em: 2 jul. 2018. 
LAYRARGUES, Philipe Pomier. Educação ambiental com compromisso social: o desafio da superação das desigualdades. In: LOUREIRO, Carlos Frederico Bernardo; LAYRARGUES, Philippe; CASTRO, Ronaldo Souza (Org.). Repensar a Educação Ambiental: um olhar crítico. São Paulo: Cortez, 2009.

LEFF, Enrique. Racionalidade Ambiental: a reapropriação social da natureza. Tradução de Luís Carlos Cabral. Rio de Janeiro: Civilização Brasileira, 2006.

MARINS, James; TEODOROVICZ, Jeferson. Rumo à extrafiscalidade sócio ambiental: tributação diante do desafio social e ambiental contemporâneo. In: SIMPÓSIO NACIONAL DE DIREITO CONSTITUCIONAL, 9., Curitiba, PR, 2011. Anais [...]. Curitiba: Academia Brasileira de Direito Constitucional, 2011. p. 170-99. Disponível em: http://www.abdconst.com.br/revista3/jamesmarins.pdf. Acesso em: 24 jun. 2019.

MEZZAROBA, Orides. Manual de metodologia da pesquisa no direito. 7. ed. São Paulo: Saraiva, 2017.

MORENILLA, Juan. Cidades gigantes, desafios gigantes: centros urbanos da América Latina precisam planos de edificabilidade, transporte e luta contra a desigualdade. El País, Madri, 11 fev. 2016. Disponível em: https://brasil.elpais.com/brasil/2015/04/09/internacional/1428595647_142720.html. Acesso em: 3 jun. 2018.

OLIVEIRA, Á.; CAMPOLARGO, M. From smart cities to human smart cities. In:. HAWAIl INTERNATIONAL CONFERENCE ON SYSTEM SCIENCES (HICSS), 48., 5-8 jan. 2015, Kauai, HI, EUA. Anais [...]. Kauai: IEEE, 2015. p. 2336-44.

ORGANIZAÇÃO DAS NAÇÕES UNIDAS. Declaração final e plano de ação. In: CONFERÊNCIA MUNDIAL SOBRE OS DIREITOS HUMANOS. Viena, 1993. Disponível em: https://www2.senado.leg.br/bdsf/bitstream/ handle/id/508144/000992124.pdf. Acesso em: 7 maio 2021.

ORGANIZAÇÃO DAS NAÇÕES UNIDAS. Comissão mundial sobre o meio ambiente e desenvolvimento. Nosso futuro comum. Nova lorque: ONU. 1987. Disponível em: https://edisciplinas.usp.br/pluginfile. php/4245128/mod_resource/content/3/Nosso\%20Futuro\%20Comum.pdf. Acesso em: 7 maio 2021.

ORGANIZAÇÃO DAS NAÇÕES UNIDAS. Declaração sobre o Direito ao Desenvolvimento. Nova lorque: ONU, 1986. Disponível em: http://www.dhnet.org.br/direitos/sip/onu/spovos/lex170a.htm. Acesso em: 3 jun. 2018.

ORGANIZAÇÃO DAS NAÇÕES UNIDAS. Declaração da Conferência das Nações Unidas sobre o meio ambiente humano. Estocolmo, 1972. Disponível em: https://legal.un.org/avl/ha/dunche/dunche.html. Acesso em: 7 maio 2021.

PETRÓPOLIS (Cidade). Lei Municipal n. 6018, de 9 de setembro de 2003. Dispõe sobre a concessão de incentivos fiscais e econômicos para empresas que se estabeleçam no Município de Petrópolis ou nele ampliem suas atividades, institui o fundo de desenvolvimento econômico do Município de Petrópolis FUNDEMP, e dá outras providências. Petrópolis, 2003. Disponível em: https://leismunicipais.com.br/a/ rj/p/petropolis/lei-ordinaria/2003/602/6018/lei-ordinaria-n-6018-2003-dispoe-sobre-a-concessao-deincentivos-fiscais-e-economicos-para-empresas-que-se-estabelecam-no-municipio-de-petropolis-ou-neleampliem-suas-atividades-institui-o-fundo-de-desenvolvimento-economico-do-municipio-de-petropolisfundemp-e-da-outras-providencias. Acesso em: 3 jun. 2019.

PETRÓPOLIS (Cidade). Lei Municipal n. 7.799, de 6 de junho de 2019. Cria a Política Pública de incentivo à inovação e à pesquisa tecnológica, ao desenvolvimento sustentável e à consolidação dos ambientes de inovação nos setores produtivos e sociais da cidade de Petrópolis e dá outras providências. Petrópolis, 2019. Disponível em: http://www.petropolis.rj.gov.br/pmp/index.php/servicos-na-web/informacoes/ diario-oficial/finish/242-junho/4511-5692-sexta-feira-7-de-junho-de-2019.html. Acesso em: 3 jun. 2019. 
PIONTKEWICZ, Regiane; FREITAS, Maria do Carmo Duarte; BIZ, Alexandre Augusto. Benefícios fiscais para incentivo à inovação tecnológica no Brasil: informação para uso no processo de tomada de decisão em indústrias de grande porte. RACEF - Revista de Administração, Contabilidade e Economia da Fundace, v. 8, n. 2, p. 31-47, 2017.

PIOVESAN, Flávia. Temas de Direitos Humanos. São Paulo: Saraiva, 2014.

SILVEIRA, Vladimir Oliveira; ROCASOLANO, Maria Mendez. Direito humanos: conceitos, significados e funções. São Paulo: Saraiva, 2010.

UNITED NATIONS HUMAN SETTLEMENTS PROGRAMME. State of the world's cities report 2012/2013: prosperity of cities. Nairobi: UN-Habitat, 2012. Disponível em: http://www.unhabitat.org/pmss/ getElectronicVersion.aspx?nr=3387\&alt=1. Acesso em: 30 jun. 2018.

VERGARA, Sylvia Constant. Projetos e relatórios de pesquisa em administração. São Paulo: Editora Atlas, 1998.

VIEIRA, Lina Maria. Educação fiscal e cidadania. Organizadora Eloísa Maia Vidal. Fortaleza: Edições Demócrito Rocha, 2010.

WEISS, Marcos Cesar. Cidades inteligentes como nova prática para o gerenciamento dos serviços e infraestruturas urbanos: estudo de caso da cidade de Porto Alegre. 2013. 167 f. Dissertação (Mestrado em xxx) - Centro Universitário da FEI, São Paulo, SP, 2013. Disponível em: http://www.academia. edu/7390000/CIDADES_INTELIGENTES_COMO_NOVA_PR\%C3\%81TICA_PARA_O_GERENCIAMENTO_ DOS_SERVI\%C3\%87OS_E_INFRAESTRUTURAS_URBANOS_estudo_de_caso_da_cidade_de_Porto_Alegre. Acesso em: 2 jul. 2018.

\section{Sobre os autores:}

Franco Guerino de Carli: Mestre em Desenvolvimento Local pela Universidade Católica Dom Bosco (UCDB). Mestrando em Direito pela Universidade Federal de Mato Grosso do Sul (UFMS). Especialista em Processo Civil e graduado em Direito pela Faculdade de Direito Santo Ângelo. Atualmente, é advogado - Senger e De Carli Advogados -, pesquisador e professor de graduação e pós-graduação na UCDB. Integrante do Grupo de Pesquisas Direito, Políticas Públicas e Desenvolvimento Sustentável e pesquisador no Grupo de Pesquisas Mecanismos Alternativos e Sustentáveis na Solução de Conflitos, junto à UFMS. Tem experiência na área de Direito, com ênfase em Direito Processual Civil, Previdenciário, Constitucional e Direito Civil. E-mail: decarlifranco@gmail.com, Orcid: http://orcid.org/0000-0001-6035-8192

Lídia Maria Ribas: Pós-doutora na Faculdade de Direito da Universidade de Coimbra, em Direito Público; na Faculdade de Direito da Universidade Nova de Lisboa em Ciências Sociais Aplicadas; e em Ciências Jurídicas e Sociais, na Universidade do Museo Social da Argentina - Instituto Educacional Almirante Tamandaré (UMSA/IEAT). Doutora e mestre em Direito do Estado pela Pontifícia Universidade Católica de São Paulo (PUC/SP). Advogada e economista, com graduação em Formação de Professores e em Administração de Empresas pela Universidade Católica Dom Bosco (UCDB). Especialista em Elaboração e Análise de Projeto de Desenvolvimento Regional, pelo Centro de Treinamento para o Desenvolvimento Econômico (IPEA-CENDEC); em Metodologia do Ensino Superior, pela Universidade Federal de Mato Grosso do Sul (UFMS); em Análise de Sistemas, pela CTIS Informática e Sistemas Ltda; em Direito Civil e Empresarial, pelas Faculdades Unidas Católicas de Mato Grosso. Pesquisadora e professora na graduação e na pós-graduação do curso 
de Direito da (UFMS). Líder do Grupo de Pesquisas Direito, Políticas Públicas e Desenvolvimento Sustentável e pesquisadora no Grupo de Pesquisas Tutela Jurídica das Empresas em Face do Direito Ambiental Constitucional, ambos do CNPq. E-mail: limaribas@uol.com.br, Orcid: http://orcid.org/0000-0003-4764-6661 